\section{SPD-039 MAKE OR BUY: PHARMACOECONOMIC EVALUATION OF GARGLE SOLUTIONS USED FOR SARS-COV-2 SAMPLE COLLECTION}

N Lindner*, D Haider. Clinic Favoriten, Pharmacy, Vienna, Austria

\subsection{6/ejhpharm-2021-eahpconf.22}

Background and importance The SARS-CoV-2 pandemic has become a major public health issue around the world. Samples for viral detection are generally obtained through nasopharyngeal or oropharyngeal swabs. Several studies have investigated gargling as an alternative method for sample collection. This offers various advantages for patients, particularly in the paediatric setting, as well as for healthcare personnel. Different media for gargling exist, which led to a pharmacoeconomic comparison of the available products.

Aim and objectives The aim of this study was to compare the cost of products, which can be used as gargling solutions for SARS-CoV-2 sample collection.

Material and methods Phosphate buffered saline (PBS) in tubes was requested by the laboratory department as a gargling solution for specimen collection in a clinical trial in children. Since no pharmaceutically approved PBS products are available, the pharmacy department could either compound the solution or commission a contract manufacturer. Physiological saline, available as a pharmaceutically approved product, could function as an alternative to PBS.

The prices of all three products and potential cost reductions were directly compared. Costs for pharmacy production were calculated, estimating an average production and packaging time of 26 hours for a batch of 1000 tubes, while running costs for available infrastructure were neglected.

Results

\begin{tabular}{ll}
$\begin{array}{l}\text { Abstract 2SPD-039 Table } 1 \\
\text { tubes }\end{array}$ & PBS: pharmacy production of 1000 \\
\hline Cost component & Price $(€)$ \\
\hline Material costs & 40.12 \\
Packaging costs & 131.92 \\
Personnel costs & 1354.60 \\
Total costs & 1526.64 \\
\hline
\end{tabular}

\begin{tabular}{llll} 
Abstract 2SPD-039 & Table 2 & Comparison of costs & \\
\hline Product & $\begin{array}{l}\text { Average cost } \\
\text { per tube }(€)\end{array}$ & Price difference (\%) & $\begin{array}{l}\text { Cost reduction per } \\
1000 \text { tubes }(€)\end{array}$ \\
\hline Physiological saline & 0.15 & -90.06 (vs 2) & -1374.94 (vs 2) \\
& & -95.22 (vs 3) & -3023.30 (vs 3) \\
PBS: pharmacy production & 1.53 & $+906,35$ (vs 1) & -1648.36 (vs 3) \\
& & -51.92 (vs 3) & \\
PBS: GMP production & 3.18 & +1992.95 (vs 1) & \\
& & +107.97 (vs 2) & \\
\hline
\end{tabular}

Conclusion and relevance While the contract manufacturer delivers GMP certified products at high cost, non-certified pharmacy productions cannot reach these quality standards. Product changes, in this case from PBS to the equally validated physiological saline, act as a valuable measure aiming at cost reductions. Pharmacy departments play an important part in evaluating availability, practicability and particularly cost effectiveness of desired products and should thus be included in the decision making process.

\section{REFERENCES AND/OR ACKNOWLEDGEMENTS}

Conflict of interest No conflict of interest

\section{SPD-040 IMPACT OF AUTOMATED DISPENSING CABINETS ON DISPENSING ERRORS, INTERRUPTIONS AND PILLBOX PREPARATION TIME}

${ }^{1} \mathrm{M}$ Jumeau*, '10 François, ${ }^{1,2} \mathrm{P}$ Bonnabry. 'Geneva University Hospitals, Pharmacy, Geneva, Switzerland; ${ }^{2}$ Institute of Pharmaceutical Sciences of Western Switzerland- School of Pharmaceutical Sciences-University of Geneva, Pharmacy, Geneva, Switzerland

\subsection{6/ejhpharm-2021-eahpconf.23}

Background and importance The pillbox preparation is an error prone act for the nursing staff and interruption is a contributing factor. Automated dispensing cabinets (ADC) have the potential to reduce error rates, but only limited evidence is available.

Aim and objectives The aim of this work was to evaluate the impact of $\mathrm{ADC}$ on the dispensing error rate, number of interruptions and pillboxes preparation time in a large scale real life study.

Material and methods This was a prospective observational study in 16 wards of two departments (medicine and surgery). We compared eight wards with an ADC (Pyxis Medstation, BD) and eight wards with a traditional dispensing cabinet (TDC) involving manual picking of drugs. Observations were made by a single observer using the disguised observation technique during the preparation hours of the pill dispensers. A picture was taken of each pillbox and the contents were compared with the information contained in the patient's electronic chart. The proportion of errors was calculated by dividing the number of doses with errors by the total number of opportunities for errors. The observer chronometered the time taken to prepare the pillboxes and noticed any interruptions. Wards participating and not participating in the 'more time for the patient' (Lean management) project were compared.

Results 2924 opportunities for error in 570 pillboxes made by 132 nurses were observed. We measured significant decreases in error rates $(1.0 \%$ vs $5.0 \%, p=0.0001)$, number of interruptions per hour (3.15 vs $5.72, p=0.008)$ and preparation time in seconds per drug (32 vs $40, p=0.0017$ ) between the ADC and TDC groups, respectively. There was a significant decrease in the error rate $(1.4 \%$ vs $4.4 \%, p=0.0268)$ and a non-significant decrease in the number of interruptions per hour $(3.80$ vs 5.06, $\mathrm{p}=0.0802$ ) between services participating in the 'more time for the patient' project and those not participating in this project, respectively. No error resulted in patient harm. Conclusion and relevance ADCs reduced dispensing errors, interruptions and time when preparing pillboxes. Services that implemented a Lean management approach had a lower error rate in comparison with non-participating services.

\section{REFERENCES AND/OR ACKNOWLEDGEMENTS}

Conflict of interest No conflict of interest 